
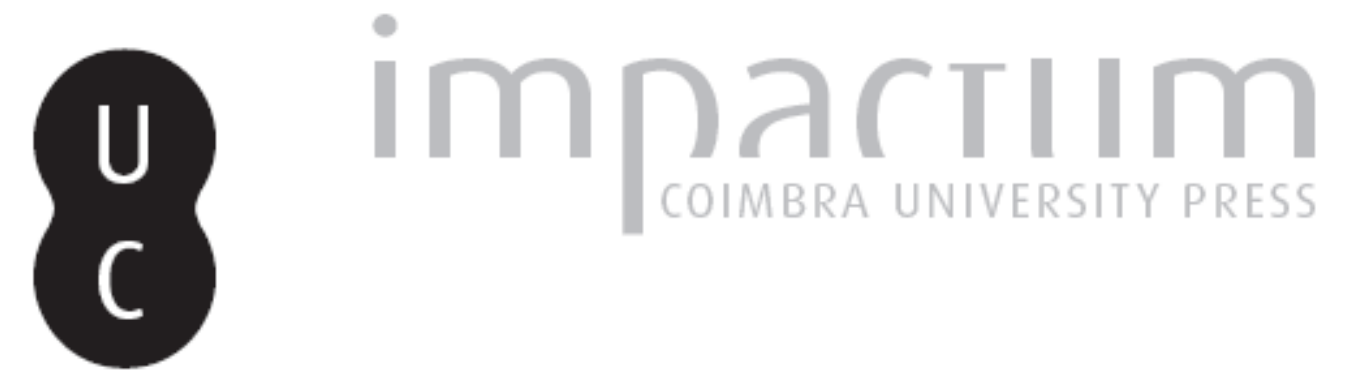

\title{
União Soviética: a outra informação
}

\section{Autor(es): Lemos, Mário Matos e}

Publicado por: Imprensa da Universidade de Coimbra

URL persistente:

URl:http://hdl.handle.net/10316.2/43704

DOI:

DOI:https://doi.org/10.14195/2183-8925_25_13

Accessed : $\quad$ 26-Apr-2023 06:31:20

A navegação consulta e descarregamento dos títulos inseridos nas Bibliotecas Digitais UC Digitalis, UC Pombalina e UC Impactum, pressupõem a aceitação plena e sem reservas dos Termos e Condições de Uso destas Bibliotecas Digitais, disponíveis em https://digitalis.uc.pt/pt-pt/termos.

Conforme exposto nos referidos Termos e Condições de Uso, o descarregamento de títulos de acesso restrito requer uma licença válida de autorização devendo o utilizador aceder ao(s) documento(s) a partir de um endereço de IP da instituição detentora da supramencionada licença.

Ao utilizador é apenas permitido o descarregamento para uso pessoal, pelo que o emprego do(s) título(s) descarregado(s) para outro fim, designadamente comercial, carece de autorização do respetivo autor ou editor da obra.

Na medida em que todas as obras da UC Digitalis se encontram protegidas pelo Código do Direito de Autor e Direitos Conexos e demais legislação aplicável, toda a cópia, parcial ou total, deste documento, nos casos em que é legalmente admitida, deverá conter ou fazer-se acompanhar por este aviso.

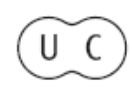



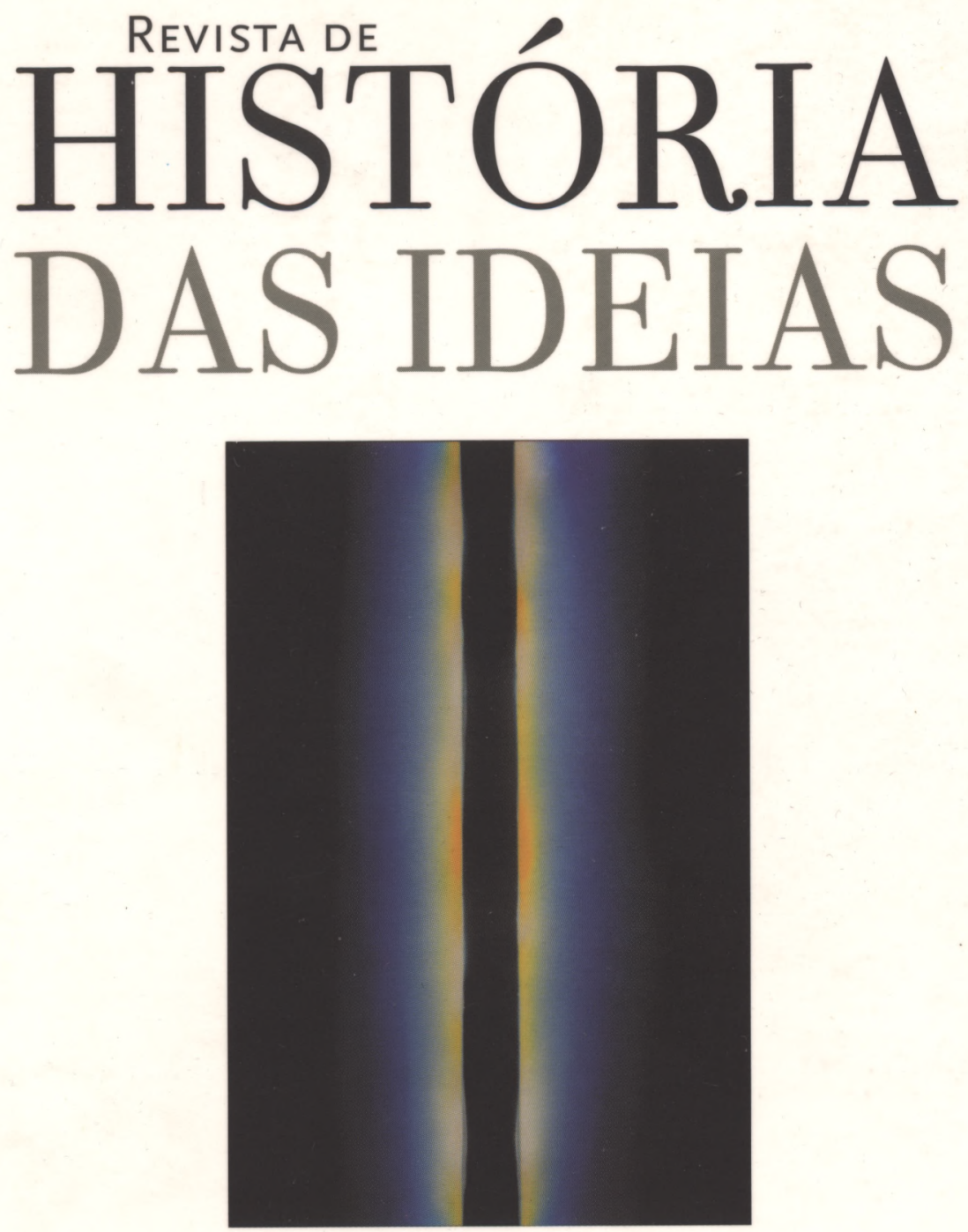

TOLERÂNCIAS, INTOLERÂNCIAS

\author{
Volume 25, 2004
}

INSTITUTO DE HISTÓRIA E TEORIA DAS IDEIAS

Faculdade de Letras da Universidade de CoImbra 


\section{UNIÃO SOVIÉTICA: A OUTRA INFORMAÇÃO}

O texto que se segue está datado de Moscovo, 5 de Dezembro de 1978, e foi enviado para o Ministério dos Negócios Estrangeiros, em Lisboa, para conhecimento. Nessa altura desempenhava eu as funções de Conselheiro de Imprensa na Embaixada de Portugal na União Soviética, sendo Embaixador o Dr. Fernando de Magalhães Cruz, um diplomata de extraordinária qualidade, a quem aqui deixo a minha homenagem. Este texto completava um outro sobre os meios de comunicação social oficiais, remetido também para o Ministério dos Negócios Estrangeiros, mas no ano anterior, em 30 de Junho de 1977. Redescoberta agora uma cópia entre papéis velhos que arrumava, pareceu-me que poderia ter interesse dar-lhe alguma divulgação, não porque seja um trabalho com pretensões académicas, pois não passa de uma simples informação de serviço; todavia, não conheço qualquer outro estudo em Portugal sobre este assunto ${ }^{(1)} e$ talvez a sua publicação desperte em alguém o interesse de aprofundar este tema que tem tudo a ver com várias disciplinas: a História, a Literatura, o Jornalismo e a Sociologia, além da Política. Aqui se publica, por isso, sem quaisquer emendas ou acrescentos em relação ao texto original. De novo, apenas as notas, todas elas, pois o texto primitivo não tinha notas. A própria bibliografia é a que usei na altura e está, certamente, ultrapassada. Como disse, porém, trata-se de um mero testemunho datado. Por fim, quero agradecer ao Prof. Doutor Luís Reis Torgal a leitura atenta que fez deste texto.

* Antigo Conselheiro de Imprensa em Moscovo.

(1) Em 1975, foi publicado pela Editorial Futura, de Lisboa, a tradução de uma obra de George Saunders, intitulada Samizdat. Vozes da Oposição Soviética, que é uma colectânea de textos clandestinos. Tem uma introdução do próprio Saunders. 
Num momento em que tanto se fala de dissidentes na União Soviética ${ }^{(2)}$ - e para além do estudo do próprio fenómeno em si - parece interessante examinar um dos aspectos mais esquecidos, mas que é fundamental, de toda a actividade dissidente: a comunicação. Sem comunicação não haveria dissidentes, como força política, entenda-se.

Ao examinar as formas de comunicação utilizadas pelos dissidentes ${ }^{(3)}$, ver-se-á, embora sem aprofundar, que a dissidência reveste numerosas formas: há os dissidentes por motivos religiosos ${ }^{(4)}$, os que pretendem a queda do regime comunista, os que simplesmente desejam a sua evolução num sentido mais liberal, os dissidentes por motivos nacionalistas (como os tártaros ou os ucranianos) e ainda os refuseniks, já não propriamente dissidentes, mas alemães de origem, e soviéticos de nacionalidade, que protestam contra o regime por não lhes ser concedido um visto de saída do país. Também, precisamente porque não se trata aqui de um estudo sobre a dissidência na União Soviética, deixar-se-ão igualmente de parte aspectos tão importantes como o das classes de cujas fileiras saem dissidentes ou as perspectivas de evolução ou de redução do movimento dissidente, o que, quanto a mim, só pode ser feito com o estudo da evolução económica da sociedade soviética.

\section{Tradição e origem do samizdat}

Samizdat é palavra conhecida e corrente tanto na URSS como no Ocidente. Define, grosso modo, os manuscritos postos a circular clandestinamente com material que não se encontra na imprensa oficial, material

(2) Recordo que me refiro ao ano de 1978.

(3) Ou "resistentes", conforme pretende Vladimir Bukhovski que numa entrevista à revista italiana Panorama ( ${ }^{\circ} 655$, de 7 de Novembro de 1978) afirmou: "Dissidente, dissidência. São palavras que vós, ocidentais, usais sempre, mas que não me agradam nada. Nas línguas europeias, em inglês sobretudo, dissidente quer dizer aquele que deixou de condividir o pensamento do seu grupo, do qual saiu. Nós, pelo contrário, nunca estivemos de acordo, nem numa vírgula, nem por um só momento na nossa vida, com o comunismo soviético. Se quereis dar-nos um nome, chamai-nos resistentes.".

(4) Na União Soviética havia, em 1970, 50 milhões de católicos ortodoxos, 30 milhões de muçulmanos, 5 milhões de católicos romanos, mais de 2 milhões de judeus, 500.000 baptistas e 253.000 budistas, segundo refere Barbara Wolfe Jancar in Dissent in the USSR, p. 197. 
esse que pode ser noticioso ou interpretativo, um conto ou um romance (como, por exemplo, o Dr. Jivago, de Boris Pasternak), poesia ou teatro.

A palavra em si é recente. Data dos anos 1960, talvez tenha aparecido um pouco antes, mas em círculos muito restritos, e não é mais do que um aproveitamento irónico da palavra Gosizdat, acrónimo de Gossudarsternnoe Izdatelsvo - a Editora do Estado. Sam significa auto ou por si próprio, pelo que samizdat pode traduzir-se por auto-edição ou edição de si mesmo (como Tamizdat - tam significa ali - é a publicação no estrangeiro das obras proibidas na URSS).

"A liberdade de expressão existe na União Soviética, mas exprime-se na actividade do que geralmente se chama samizdat" - afirmou o então jovem escritor Jorge Vladimov numa carta que dirigiu ao IV Congresso dos Escritores Soviéticos, em Maio de 1967, a qual, durante muito tempo circulou ela própria sob a forma de samizdat e que é o primeiro documento a utilizar essa palavra destinada a tornar-se famosa.

A partir de 1968, o samizdat, se reunido, constituiria já uma verdadeira biblioteca: só até 1971 chegaram ao Ocidente cerca de 700 publicações, inserindo documentos, artigos, obras literária em prosa e em verso, teatro ou romance. E é lícito pensar que se tratasse apenas da ponta de um "iceberg". Possuir, divulgar e, muito mais, fazer chegar ao estrangeiro obras clandestinas era, e é(5), face à lei soviética, crime cuja sanção não é branda.

O samizdat não é, porém, algo de novo no território que é hoje o da União Soviética. Em 1790, um funcionário de alfândega, Alexandre Radistshev, escreveu e mandou imprimir um livro contra o sistema do trabalho servo, intitulado Uma Viagem de Petersburgo a Moscovo; o livro acabou por ser proibido e dos 650 exemplares da tiragem só 17 escaparam de ser confiscados, passando a circular de mão em mão, clandestinamente ${ }^{(6)}$. Por alturas de 1820, escritores como Puskine ${ }^{(7)}$ e Griboyedov ${ }^{(8)}$ fizeram circular manuscritos em que podiam ler-se obras que aos

(5) Mais uma vez se recorda que este texto foi escrito em 1978.

(6) Episódio referido por Gayle Durham Hollander in Dissent in the USSR, p. 263.

(7) Alexander Sergueievich Puskine (1799-1837), poeta e dramaturgo, autor de obras tão importantes como Eugénio Onieguine, Boris Godunov ou A Dama de Espadas.

(8) Alexander Sergueievich Griboïedov (1795-1829), diplomata e dramaturgo, autor de uma famosa sátira da sociedade russa intitulada $A$ Infelicidade de ser Inteligente. 
censores da época não agradavam; se no reinado de Alexandre $\mathrm{II}^{(9)}$ a atmosfera política de maior liberdade e a circulação clandestina mas tolerada do jornal de Herzen ${ }^{(10)}$, $O$ Sino, reduziram o apetite pela leitura de manuscritos mais ou menos clandestinos e mais ou menos literários, nem por isso se evitou que começassem a aparecer manifestos e folhetos de carácter político, tendência que viria a acentuar-se com a formação dos primeiros grupos políticos ilegais, pelos anos 60 .

Entre Março e Outubro de 1917, a Rússia vive o seu único período de total liberdade de imprensa e é nesta altura, portanto, que não se encontra qualquer publicação ilegal. Com a chegada dos bolcheviques ao poder, essa liberdade desaparece. $O$ "Decreto sobre Imprensa" e a "Regulamentação Geral da Imprensa" são assinados por Lenine em 27 de Outubro e 9 de Novembro de 1917, respectivamente. Ficam proibidos todos os jornais não bolcheviques e são impostas medidas censórias. Naturalmente que se dizia tratar-se de medidas extraordinárias e temporárias destinadas a serem revogadas "quando a vida pública regressar à normalidade". Nunca aconteceu e em $1922 \mathrm{a}$ Censura deixou de pertencer ao Gosizdat para ser entregue ao Glavlit (acrónimo da então Direcção-Geral para a Protecção do Estado e dos Segredos Militares na Imprensa, dependente do Conselho de Ministros): 6 de Junho de 1922 é a data da introdução da censura oficial, embora já existisse, como se disse, desde 1917.

A partir de então, a história da imprensa, ou comunicação, clandestina (aqui as palavras imprensa ou comunicação têm de ser entendidas de forma muito ampla, abrangendo toda a espécie de trabalhos, desde os noticiosos aos literários, passando pelos panfletos e que geralmente nada têm a ver com a forma impressa, pois surgem quase sempre sob forma dactilografada) confunde-se com a história da oposição na União Soviética.

Sob Lenine ${ }^{(11)}$, e principalmente sob Estaline ${ }^{(12)}$, a comunicação clandestina não tem grande relevância, ou melhor, tem alguma importância para as obras literárias. $\mathrm{O}$ impulso revolucionário, a guerra civil, as radicais

(9) Czar da Rússia, filho de Nicolau I, nasceu em 1818 e sucedeu ao pai em 1855. Foi assassinado por nihilistas em 1881.

(10) Alexander Ivanovich Herzen - (1812-1870), escritor e revolucionário russo. Morreu exilado em Paris.

(11) Vladimir Ilitch Ulianov, chamado Lenine - (1870-1924).

(12) Josif Vissarionovitch Djugachvili, chamado Estaline - (1879-1953). 
mudanças sociais, o desaparecimento da antiga intelligentzia e, depois, o terror sob Estaline relegam a comunicação clandestina para um plano secundário. A ousadia de Riutine de fazer circular um manifesto anti-Estaline, em 1932, ou a de Mandelsthan ${ }^{(13)}$, que pagou com a vida um poema de 14 versos, ficaram praticamente sem exemplo.

Ironicamente - trágica ironia - é no final dos anos 30, nos campos de concentração, que nasce uma riquíssima literatura de canções, com letras fortemente politizadas e que se desenvolve uma concepção de liberdade de expressão e de comunicação que haveria de dar os seus frutos na era post-estalinista, especialmente depois do XX Congresso do Partido Comunista da URSS, em 1956.

\section{Desestalinização e Literatura}

Há, todavia, um aspecto muito importante que me parece não poder ser descurado. $\mathrm{O}$ discurso de $\mathrm{Kruschov}^{(14)}$ nesse congresso dá origem à desestalinização ou vem simplesmente inserir-se, para aproveitá-la politicamente, numa corrente mais liberal?

Apenas poucos meses depois da morte de Estaline, o escritor Vladimir Pomerantzev lançava na revista Novy Mir (Novo Mundo), dirigida desde 1950 por Alexandre Tvardovski e considerada baluarte dos "liberais", um apelo a favor da "sinceridade" em matéria de expressão literária. "A hipocrisia - lê-se ali - não se exprime necessariamente por uma mentira. Até a maneira de apresentar uma coisa pode ser hipócrita [...] Tudo o que é estereotipado, tudo o que não provém do próprio autor, é hipócrita".

Tratava-se de um verdadeiro protesto contra os chamados "critérios zdanovitas", de André Zdanov, Secretário do Partido Comunista da União Soviética (PCUS), normas essas expostas por várias vezes entre 1946 e 1952 e que se referiam especialmente ao conteúdo e à técnica dos

(13) Osip Emilievitch Mandelsthan (1891-1938), filho de um comerciante judeu, nasceu em Varsóvia e desapareceu numa das purgas dos anos 30; é considerado um dos maiores poetas russos do século XX.

(14) Nikita Sergueievitch Kruschov - (1894-1971) - Primeiro Secretário do Comité Central do PCUS (1953-1964) e Presidente do Conselho de Ministros da URSS (1958-1964). 
romances como dos poemas, do ensaio como do teatro. Esta oposição dos direitos do artista criador, da sinceridade do autor, aos dogmas do Partido era, afinal, a base de toda uma teoria política, era o fundamento de uma luta que iria travar-se entre - chamemos-lhe assim, para simplificar - liberais e conservadores. Provocou imediatamente forte reacção de escritores e de funcionários do Partido (Pomerantsev foi acusado de "ter usado as páginas da revista para atacar os fundamentos ideológicos da literatura soviética") e Tvardovsky foi demitido. Era o mês de Agosto de 1954.

Ora, sabe-se que logo no início de 1954 já circulavam clandestinamente antologias de poesia, principalmente nos centros universitários. Em 23 de Dezembro de 1955, a Konsomolskaia Pravda (jornal diário, órgão das juventudes comunistas) revelava a existência na Universidade de Vilnius de um jornal clandestino chamado Folha de Parra e, ao mesmo tempo denunciava (fora para isso que revelara, claro) "o carácter demagógico e o espírito vulgar" dos poemas ali publicados. Alguns dias depois, o mesmo quotidiano assinalava o aparecimento na Universidade de Leninegrado de um jornal manuscrito, O Botão Azul, considerando que "os contos miseráveis e os poemetos infamantes" só podiam ter aparecido devido "ao nível imperdoavelmente baixo do trabalho ideológico entre os estudantes". Outras publicações foram também denunciadas pela imprensa oficial, como por exemplo Heresia e As Vozes Novas, ambas de Leninegrado: a primeira do Instituto Krupskaia, a segunda da Escola dos Engenheiros do Caminho de Ferro.

Outro sinal revelador de que o novo espírito se difundia, e já não só entre os estudantes, foi o discurso de Constantino Simonov ${ }^{(15)}$ no II Congresso dos Escritores da URSS, reunido em 15 de Dezembro de 1954 (20 anos depois do I Congresso, que data de Agosto de 1934, o que tem também o seu significado). "Todos os pontos de vista expressos abertamente ou por meias palavras e tentando desviar a literatura da luta activa a favor do comunismo - observou Simonov - representam para nós, não pontos de vista discutíveis mas, muito pelo contrário, pontos de vista radicalmente hostis ao próprio espírito da literatura soviética." (Era a reafirmação do "realismo socialista" proclamado em 1934).

(15) Kiril Mikhailovitch Simonov, chamado Constantino (1915-1979), poeta, escritor e dramaturgo russo. 
É este, portanto, o contexto em que se reúne, a partir de 14 de Fevereiro de 1956, o XX Congresso do Partido Comunista da União Soviética, ao qual Kruschov apresenta, no dia 25, o seu famoso relatório "sobre o culto da personalidade e as suas consequências".

Embora não tivesse sido tornado público, o relatório do Secretário Geral do PCUS não tardou a ser conhecido dos meios intelectuais, que logo compreenderam o rude golpe que dava às posições dogmáticas. Era praticamente a luz verde para um degelo (como se lhe chamou) que se fez sentir em todos os domínios artísticos: literatura, teatro, cinema, música, pintura, e que talvez tivesse acabado por contribuir poderosamente para a queda de Kruschov, na medida em que os escritores e artistas eram parte do seu jogo político baseado - ao longo dos anos, com altos e baixos - na desestalinização. Desse jogo político, faz parte, por exemplo, a publicação do poema de Ievutchenko ${ }^{(16)}$ "Os Herdeiros de Estaline" (na Pravda, de 21 de Outubro de 1962, mas muitas vezes recitado em público anteriormente) e a do conto de Soljenietsine ${ }^{(17)}$ "Um dia na Vida de Ivan Denisovitch", igualmente aparecido no fim de 1962. A história da publicação desta longa novela na já citada revista Novy Mir, dirigida outra vez por Alexandre Tvardovski (que estivera afastado entre Agosto de 1954 e Junho de 1958, tendo sido substituído nesse interim por Constantino Simonov), pode ajudar a fazer uma certa luz sobre os acontecimentos ou, talvez, a permitir apenas uma certa interpretação desses acontecimentos.

Antes, porém, deve notar-se que o ambiente que permitiu a euforia da Primavera de 1956 - quando Ehrenburg ${ }^{(18)}$, à frente de um grupo de escritores, fez publicar sem o visto da Censura dois números de uma grossa revista chamada Moscovo Literária, e quando Ievutchenko, então com 23 anos, publica o seu poema Estação Zima, tornando-se o ídolo da juventude - sofreu rude golpe com a revolta da Hungria (23 de Outubro de 1956), inquietando seriamente os dirigentes moscovitas. A revolução húngara não fora preparada por movimentos de intelectuais? Não seria um erro autorizar as discussões nos meios literários e estudantis?

(16) Evgueni Alexandrovitch Ievtuchenko (1933-), poeta russo.

(17) Alexander Issaievitch Soljenietsine (1918-), escritor dissidente russo.

(18) Ilia Grigorievtch Ehrenburg (1891-1967), escritor russo, autor de O Degelo, publicado em 1954, obra cujo título viria a significar o período de desestalinização. 
Os conservadores retomaram alento e quando, em 1957, Boris Pasternak ${ }^{(19)}$ propôs a publicação do seu romance Dr. Jivago, já era tarde.

Este endurecimento terá como uma das consequências fazer agrupar o campo liberal em torno da revista Novy Mir e como a luta entre as duas facções nunca se extingue, mau grado o "aviso" que fora a revolta húngara, é nessa revista que aparecerá Um Dia na Vida de Ivan Denisovitch, vejamos em que condições.

Apresentada à leitura no início de Dezembro de 1961 - ou seja, dois anos depois de, no XXII Congresso do PCUS, ter sido decidido expulsar o embaraçoso cadáver de Estaline do mausoléu que compartilhava com Lenine - a novela de Soljenietsine foi lida e relida pela comissão de redacção com entusiasmo, mas desde logo se compreendeu que se estava perante um problema político: um parágrafo das disposições do Glavlit especificava que o tema "lugares de detenção" caía sob a alçada do "segredo de Estado" e aquela novela podia, além do mais, abrir o caminho à literatura dos campos de concentração, à roda dos quais - e da reabilitação dos que por lá haviam passado ou morrido - se travava uma luta surda. Todavia, Tvardovski, com o apoio de toda a comissão de redacção, resolveu escrever uma carta a Kruschov pedindo a aprovação do manuscrito. "Sabe-se - escreveu o crítico literário soviético Vladimir Lakchine - que a publicação foi finalmente decidida pelo Presidium da Comissão Central do Partido Comunista da União Soviética depois de discutida em duas sessões; e, no entanto, depressa se viu que Um Dia na Vida de Ivan Denisovitch tinha inimigos que não deixavam de ser influentes".

Se o início da "liberalização" de Kruschov (que nunca foi "liberal" mas usou o "liberalismo" como arma) tem uma data, o do seu volta-face é igualmente datável: 1 de Dezembro de 1962 (embora muito anunciado desde o fim de 1956); nesse dia, ao visitar, na Galeria do Picadeiro, em Moscovo, uma exposição de pintura que ia ser inaugurada no dia seguinte, Kruschov foi encontrar, entre dois mil quadros e esculturas, umas sete dezenas de obras de vanguarda, apesar de tudo muito menos

(19) Boris Leonidovitch Pasternak (1890-1960) - escritor russo, foi-lhe atribuído em 1958 o Prémio Nobel da Literatura, que foi obrigado a recusar. Morreu em desgraça e só foi reabilitado em 1987. 
ousadas do que as suas congéneres ocidentais. Foi a gota de água (e pessoalmente até penso que poderá ter sido o pretexto, embora pareça provado que Kruschov ignorava a presença daqueles quadros na exposição) para a reviravolta pública do Secretário-Geral do PCUS, e à cena de fúria in loco, certamente sincera - durante a qual Kruschov proferiu a sua célebre frase de que não se poderia admitir a exibição de obras que mais pareciam pintadas "com a cauda de um burro" (ignorando certamente, na sua rudeza, que "A Cauda do Burro" fora o nome que se atribuíra um grupo de pintores surrealistas russos do início do século) -, seguiu-se duas semanas depois, a 17, um amplo debate, organizado pelo Secretário Geral do PCUS, na presença do Presidium, com duas centenas de representantes das letras e das artes - músicos, escritores e artistas plásticos. Para além das invectivas de Kruschov e do porta-voz do Partido, Leonid Ilitchev, contra os intelectuais, aos quais se exigia, ou reexigia, absoluta submissão ao realismo socialista, de positivo nada se concluiu, salvo que a confusão na demarcação entre lícito e ilícito era total. Todavia, esta reunião foi o sinal para o início do contra-ataque dos conservadores que, habilidosamente, abriram apenas fogo contra um dos expoentes literários soviéticos: Ehrenburg. Este, nas suas Memórias, publicadas pela Novy Mir, afirmara saber que eram falsas as acusações feitas contra muitos dos condenados na época das grandes depurações (1937-1938) mas que havia cerrado os dentes e se calara. Afirmação grave, na medida em que contradizia a versão de Kruschov no XX Congresso: "Estaline organizou tudo. Nós nada sabíamos".

Em Março de 1963, Kruschov, que no XXII Congresso do PCUS afirmara ser necessário dizer ao povo toda a verdade sobre Estaline, proclamava que nada mais havia a revelar e reafirmava que os dirigentes do Partido nada sabiam sobre a falsidade das acusações.

Era, efectivamente, o fim da liberalização.

A semente, porém, estava lançada e o simultâneo desenvolvimento da sociedade soviética - melhor teor de vida, mais tempos livres, mais fácil acesso aos meios de comunicação estrangeiros, especialmente às emissões de rádio, terreno extremamente propício a tal tipo de semente - faria o resto. De então para cá, assiste-se a uma confrontação, já não discreta, mas clara, entre o Poder constituído e os que, sob uma forma ou outra, por um ou outro motivo, se lhe opõem. 


\section{O desenvolvimento do samizdat}

A partir de 1963, começou, portanto, a tornar-se cada vez mais difícil aos escritores pronunciarem-se mais ou menos livremente, como lhes ia sendo possível, quer em algumas publicações oficiais, embora sujeitas a censura, quer em publicações não oficiais, autênticos samizdat, portanto, mas de certo modo toleradas (indicavam o nome do director), como por exemplo Sintaxe (três números publicados entre 1958 e 1960), Fénix (um número editado em 1961 e reeditado em 1966) e Esfinge (1965), dirigidas, respectivamente, por Alexandre Ginzburg, Iuri Galanskov e Valério Tarsis. Outros escritores começaram a publicar as suas obras no estrangeiro: o próprio Tarsis, Boris Pasternak, Alexandres EssenineVolpine (filho de Sérgio Essenine), André Sinyavski, Iuli Daniel, Miguel Naritza, Ana Akmatova...

Ainda sob Kruschov, começara o hábito das manifestações. A primeira verificou-se em Novembro de 1961, na Praça Maiakovsky (onde, em Outubro desse mesmo ano, levutchenko recitara, aplaudido por uma multidão que o levara em triunfo, os seus poemas inconformistas) e foi descrita, em termos estupefactos e indignados, na revista Extremo Oriente (n. 2, de 1962), por um membro do Partido.

"Notei uma grande multidão que rodeava o monumento. Pareceume que estavam a ser lidos versos. Que maravilha - disse para mim, comovido. Versos junto ao monumento a Maiakovsky: os poetas modernos consagram as suas obras ao tribuno da revolução. Abri passagem. Efectivamente, um jovem declamava em voz alta ao pé do monumento. Mas que diz ele? É uma espécie de cozinhado modernista, feito por um analfabeto e pomposamente intitulado Manifesto Humano. Porco, gritei tentando obrigá-lo a descer da sua tribuna. Mas alguns jovens agarraram-me e empurraram-me brutalmente, ameaçando-me: Toma cuidado, velhote, senão damos-te uma ensaboadela para que saibas exactamente onde está a verdade."

(Diga-se que este Manifesto Humano, da autoria de Galanskov, era um verdadeiro apelo à revolta: Não acrediteis nos ministros, nos dirigentes, nos jornais / Em pé, vós que jazeis! / Vede! As bolas da morte atómica / Rolam nas órbitas do Mundo. / Em pé! Em pé! Em pé / Ó sangue escarlate da revolta! / Ide, acabai de demolir / A prisão carunchosa do Estado / Ide por entre os grupos receosos / Roubar para 
aqueles que têm fome / As bombas negras como ameixas sobre as portas da cidade...).

A queda de Kruschov, em 14 de Outubro de 1964, provocou novas medidas contra a corrente - ou as correntes - liberal, medidas essas, porém, sem grande coesão, o que traduzia bem o embaraço dos aparatchiki ${ }^{(20)}$, os quais continuavam a não conseguir traçar uma linha entre o permitido e o proibido. Começam, ou melhor, recomeçam, as prisões ou os internamentos em hospitais psiquiátricos ${ }^{(21)}$. A polícia é obrigada a intervir (14 de Abril de 1985) para dispersar uma manifestação de jovens intelectuais que percorrem as ruas de Moscovo ostentando cartazes em que se lêem frases exigindo a liberdade de expressão; estala o caso Siniavski-Daniel (dois dissidentes presos em Setembro de 1965); nova manifestação pública em Dezembro de 1965, outra vez dispersa pela polícia; são presos (Abril de 1966) os críticos literários Ivan Svitlyxchni e Ivan Djuba, acusados de terem feito chegar ao estrangeiro manuscritos - que circulavam já clandestinamente de mão em mão - do poeta Simonenko, ucraniano morto de cancro em 1967 e cujos poemas exprimiam revolta contra a burocracia; em 22 de Janeiro de 1967, nova manifestação, desta vez na Praça Puskine, que será desde então o ponto preferido para a realização de todas as manifestações; prisão, pouco depois, de membros de um grupo clandestino denominadoS.M.O.G. (das iniciais das palavras russas Valentia, Pensamento, Imagem e Profundidade): Vadim Delaune, Eugénio Kuchev e Vladimir Bukhovski. Ginzburg, director do Sintaxe, escreve uma longa carta a Kossiguine ${ }^{(22)}$, exigindo a aplicação na URSS da Declaração dos Direitos do Homem, aprovada pela ONU e ratificada pela União Soviética. Enfim, alguns casos mais conhecidos, entre muitos outros.

É neste contexto que começa o boom, passe o termo, do samizdat.

(20) Palavra que designa os funcionários do Partido Comunista.

(21) A partir de meados dos anos 60, algumas figuras de prestígio - como o general de divisão Piotr Grigorienko (1907-1982) - críticas do regime, foram consideradas loucas e internadas em hospitais psiquiátricos.

(22) Alexei Nocolaievitch Kossiguine (1904-1980), economista, sucedeu a Kruschov como Presidente do Conselho de Ministros (1964-1980). 


\section{A concepção de liberdade de informação no samizdat}

Antes de referir os principais samizdat periódicos, convém falar da concepção de liberdade de imprensa ${ }^{(23)}$ defendida - e posta em prática por esses meios de comunicação.

Um dos principais, a Crónica dos Assuntos Correntes, afirma que pretende ser, "como outros samizdat, um exemplo da liberdade de palavra e de imprensa, da liberdade de criação e da liberdade de consciência". Trata-se de um belo amontoado de palavras onde cabe tudo - incluindo a própria concepção oficial - mas pode dizer-se que, entre os autores que escrevem nestas publicações clandestinas, a concepção dominante sobre essas liberdades é a apontada por Roy Medvedev no seu livro Sobre a Democracia Socialista.

"As liberdades de palavra, de imprensa e de criação científica e artística - escreve Medvedev - são evidentemente indispensáveis a uma sociedade socialista. A imprensa e a palavra são armas poderosas da luta ideológica e política. Toda a arma tem as suas regras de utilização. A liberdade de imprensa não poderia ser, portanto, absoluta, e é natural que, numa sociedade socialista, lhe sejam impostas restrições razoáveis. Certas limitações da liberdade de imprensa devem inscrever-se no activo e não no passivo da sociedade soviética.

Nós jamais atingiremos o tipo de liberdade de imprensa que existe nos países capitalistas e não há para isso motivos de queixa. Se reivindicamos a liberdade, nem por isso tomamos como modelo a dos países capitalistas. É verdade que existe nesses países uma quase total liberdade da imprensa burguesa e da imprensa operária, incluindo a imprensa

(23) Como se sabe, liberdade de imprensa no sentido que lhe dão as democracias ocidentais, não existia na União Soviética, mas também não existia Censura. Os jornalistas, formados nas escolas de Jornalismo do país, sabiam muito bem o que podiam, ou não podiam, escrever. Em caso de dúvida, lá estavam o Director ou o Chefe ou Subchefe de Redacção. Além disso, seguindo a regra de Lenine, cada jornal pertencia a uma instituição e era dirigido a um público. Assim, nos jornais publicados em Moscovo encontramos, por exemplo, a Pravda (Verdade), órgão do Partido Comunista, as Izvestia (Novidades), órgão do Governo, o Trud (Trabalho), órgão dos sindicatos, o Krasnaia Zvezda (Estrela Vermelha), órgão do Exército, etc.. Nada se fazia ao acaso: o jornal em que uma notícia era publicada ou o local em que era inserida, tudo tinha o seu significado. 
comunista cuja influência é grande em numerosos países da Europa Ocidental [...] A maior parte da imprensa ocidental distingue-se por um aspecto mercantil que seria inadmissível numa sociedade socialista. As agências de informação e a imprensa dos países capitalistas são empresas comerciais cujo móbil essencial é o lucro. Para aumentar a tiragem, os jornais e as revistas capitalistas estão prontos não só a deformar a verdade, mas também a transgredir as regras mais elementares da moral e das conveniências...".

Que seja ou não seja esta a opinião geral dos dissidentes - Medvedev é, apenas, um dos expoentes de uma das correntes - a verdade é que todo o samizdat periódico se mantém bastante dentro destes limites. Aliás, também é necessário entrar em linha de conta com toda uma habituação a determinado tipo de informação, o da imprensa oficial soviética. No seu famoso livro Os Russos, o jornalista Hedrick Smith conta um episódio passado com ele próprio e com o seu colega Robert Kaiser, de um lado, e com Alexandre Soljenietsine, do outro. Convocados por este ao seu apartamento, por intermédio de Medvedev, Smith e Kaiser receberam das mãos do escritor um extenso manuscrito intitulado "Entrevista ao New York Times e ao Washington Post", no qual se alinhavam, umas por debaixo das outras, perguntas e respostas inteiramente preparadas pelo escritor. Smith comenta: Que ironia - pensava eu; é assim que se faz na Pravda e aqui está Soljenietsine, o homem firmemente contrário à censura, aquele que, na grande tradição de Puskine e de Dostoiewski, ousou reivindicar a independência total do escritor, que nos entrega uma entrevista que fabricou de uma ponta à outra. Como é que ele podia ser tão cego ou tão autosuficiente?

\section{O samizdat como meio de comunicação política interna}

O samizdat é apenas um dos meios de comunicação de política interna. Os outros são:

- Magnitizdat - comunicação por meio de cassetes gravadas (magnetofone é o termo russo para gravador);

- Samokino - comunicação por meio de filme (clandestino, entenda-se); e

- Samofir - comunicação via rádio (amador, claro); 
$\mathrm{Na}$ União Soviética é também eficiente, por digna de crédito, a comunicação de viva voz, de uma pessoa para outra ${ }^{(24)}$.

Como diziam sabiamente os latinos, verba volant, scripta manent e é por isso que ao samizdat cabe a parte de leão na importância para o conhecimento da "outra realidade" soviética, embora para o cidadão soviético seja com certeza a comunicação pessoal - que nada tem a ver com o boato - a principal fonte de conhecimento dessa "outra realidade".

Seria inútil e fastidioso - além de impossível - apresentar uma lista completa dos samizdat aparecidos na União Soviética, mesmo só entrando em linha de conta com os publicados depois de 1956.

O mais conhecido, mais citado, alvo já de estudos importantes, é a já referida Crónica dos Assuntos Correntes, que nasceu em 30 de Abril de 1968 e de que até hoje (Dezembro de 1978) saíram 49 números, o último dos quais datado de 14 de Maio findo.

A Crónica, mantém as características de um jornal como qualquer outro e procura evitar toda a emotividade nos seus escritos, embora represente o que se tornou conhecido como "movimento democrático", ou seja, a defesa da legalidade e dos direitos do homem, com referência à própria Constituição soviética ${ }^{(25)}$. Aliás, desde o primeiro número a

(24) Na União Soviética, as informações que chegavam às pessoas eram, de maneira geral, fiáveis. $\mathrm{O}$ próprio Partido Comunista recorria a esse tipo de divulgação de notícias quando não queria transmiti-las oficial e publicamente (Cf. Raymond A. Bauer e David B. Gleicher, "Word-of-Mouth Communication in the Soviet Union", Public Opinion Quarterly, vol. 17, n 3, Jul. 1953.

(25) A título de exemplo, reproduz-se o sumário do número 49, de 14 de Maio de 1978, em cujo cabeçalho se lia: A LUTA PELOS DIREITOS DO HOMEM NA UNIÃO SOVIÉTICA CONTINUA (Transcrição do Art ${ }^{\circ} .19$ da Declaração dos Direitos do Homem).

SUMÁRIO: Julgamento de Kiril Podranik; Julgamento de Gregori Goldstein; Julgamento de Marinobitch e Matuchbitch; Julgamento de Piotr Vins; Julgamento de Gaianskas

- Inquéritos do grupo de Helsínquia: (O caso Ginzburg; o caso Orlov; o caso Sharanski; o caso Lukianenko)

- Prisões, buscas e interrogatórios; Nas prisões e nos campos de trabalho: (Prisão de Vladimir; Campo da Mordávia; Campo de Perm; Cartas e declarações dos presos políticos; libertações; no exílio; em hospitais psiquiátricos: em hospitais psiquiátricos especiais; em hospitais comuns.

Perseguição dos tártaros da Crimeia (na Crimeia; no Uzbequistão).

Acontecimentos na Lituânia: Prisões e interrogatórios; Perseguição de crentes 
Crónica indicou na primeira página a sua adesão à Declaração Universal dos Direitos do Homem, aprovada pela ONU, incluindo o "sim" soviético, transcrevendo o seu artigo 19. No número 6 (fim de 1968), passou também a figurar na primeira página a frase "O Ano dos Direitos Humanos na União Soviética Continua". No número 12 (início de 1970) nova substituição de frase, agora mais incisiva: “O Movimento de Defesa dos Direitos do Homem na União Soviética Continua".

"A Crónica - lê-se no seu número 8 - procura manter um tom calmo e comedido. Infelizmente, os materiais com que trabalha provocam reacções emocionais e estas, automaticamente, influem no tom do texto. A Crónica faz e fará tudo o que puder para assegurar que o seu estilo absolutamente factual seja mantido no mais alto grau possível, mas não pode garantir completo êxito [...] em alguns casos é-se obrigado a fazer uma apreciação dos factos, pois de outra maneira o seu significado pode escapar ao leitor impreparado [...] A Crónica dedica-se expressamente à questão dos direitos humanos, mas como outros samizdat é um exemplo da liberdade de palavra e de imprensa, da liberdade de criação e da liberdade de consciência".

Por outro lado, a Crónica considera-se legal na medida em que é um simples repositório de acontecimentos verdadeiros e o direito soviético não considera crime o relato da verdade.

"A Crónica - escreve-se no seu número 5 - não é, em sentido algum, uma publicação ilegal e as difíceis condições em que é produzida são criadas pelas noções especiais sobre leis e liberdade de informação que ao longo dos anos foram estabelecidas em determinadas organizações soviéticas".

O tom de extrema moderação de todo o conteúdo da Crónica, juntamente com a credibilidade da sua informação, granjearam-lhe rapidamente uma aura de respeitabilidade, ao mesmo tempo que, analisando o seu estilo, se estabelecia a conviç̧ão de que era predominantemente redigida por homens de formação técnica e não literária. Em termos jornalísticos, pode dizer-se que é dotada de uma ampla rede de correspondentes: o número 1 inseria correspondência de nove localidades, mas o número 11 acrescen-

Perseguição dos crentes: (ortodoxos; católicos na Geórgia; adventistas; baptistas; prisão de Chelkov).

Direito de saída: (judeus) - discussão do projecto da Constituição na Geórgia - várias notícias - cartas e declarações - notícias do samizdat. 
tava já a essas mais dezanove, abrangendo, praticamente, todo o território da União Soviética.

Embora surgida com aspirações a quinzenal, até Outubro de 1972 apareceram apenas 27 números, com formato e número de páginas irregulares; por exemplo, o número 3 tinha duas mil palavras, mas o número 11 já era constituído por dezasseis mil palavras. Entre 1972 e 1973, a Polícia conseguiu praticamente desmantelar a Crónica: foram efectuadas numerosas prisões, designadamente as dos cientistas Piotr Iakir e Vítor Krasine e a da poetisa Natália Gorbanevskaia, esta acusada de ser directora de "um jornal que apresenta a realidade soviética sob luz criminosa", única referência à Crónica, e velada, na imprensa oficial. Todavia, a publicação reapareceu em Maio de 1974 - com nada menos de três números nesse mês - prosseguindo pelo menos até Maio do ano em curso ${ }^{(26)}$. As dificuldades de composição do material podem imaginarse. Como a própria Crónica escreveu, não pode, ao contrário de qualquer outro jornal, indicar a morada na última página. Por isso, aconselha os seus leitores a que se tiverem alguma notícia a dar comuniquem-na a quem lhes entregar a sua cópia da publicação que este, por seu turno, passá-la-á ao seu contacto e assim sucessivamente. É, afinal, o "boca a boca" a funcionar como agência noticiosa.

\section{Outras publicações}

Para além da Crónica, que é, digamos, a quinta-essência das publicações periódicas clandestinas da URSS, de entre as revistas clandestinas político-sociais que começam a proliferar cerca de 1965, distinguem-se:

- Tetrad (O Caderno) - porta-voz de um mal identificado grupo social-democrata;

- Russkoye Slova (A Palavra Russa) - editado por um grupo que pretendia entroncar-se nas tradições dezembristas ${ }^{(27)}$;

(26) 1978 .

(27) Dezembrismo, nome por que ficou conhecida uma tentativa revolucionária para impedir a subida ao trono de Nicolau I, em Dezembro de 1826. 
- Kolokol (O Sino - ou seja: o mesmo nome da famosa publicação de Herzen) periódico criado por dois estudantes do Instituto de Tecnologia de Leninegrado, Valério Ronkine e Sérgio Sakhaiev, que em 1963 haviam sido elogiados pela imprensa oficial em consequência da sua luta contra o hooliganismo. Só que o contacto com os problemas sociais desses "parasitas" despertou em ambos a consciência crítica e quando o processo de desestalinização parou, Ronkine e Sakhaiev recearam o regresso aos antigos métodos e lançaram-se na denúncia das personalidades estalinistas que continuavam no Poder. Antes de serem presos, ainda puderam publicar dois números do Kolokol.

A Crónica surge, como se disse, em 1968, e o seu estilo, a sua maneira de fazer, influenciam consideravelmente as publicações que se lhe seguem, como:

- Ukrainsky Visnyk (Aurora da Ucrânia) - O primeiro número data de Fevereiro de 1970 e atribuía-se a mesma tarefa da Crónica: informar os leitores das violações dos direitos humanos na URSS em geral e na Ucrânia em particular e dar-lhes a conhecer as iniciativas da intelligentzia ucraniana para a democratização do regime; todavia, negando ser órgão de informação de qualquer partido, o Mensageiro ressalva antecipadamente uma eventual acusação de estar ligado a algum dos movimentos separatistas ainda vivos, nessa altura, na Ucrânia.

- Iskhod (Exodo) - pelo título, pela apresentação (na primeira página, um Salmo e o art $^{\circ} .13$ da Declaração dos Direitos do Homem) e pelo conteúdo, era uma publicação dos dissidentes judeus. Começou a publicar-se em 1970 e tem como subtítulo Colecção de Documentos: mensagens, declarações, textos de leis e de decretos relacionados com medidas repressivas do Governo soviético relativamente aos judeus. O número 4 (1971) foi inteiramente dedicado ao julgamento de Leninegrado (15-24 de Dezembro de 1970) que viu a condenação de várias personalidades de nacionalidade judaica envolvidas na luta pela livre emigração. 
- Iton Alef e Iton Bet (Jornal A e Jornal B) - duas publicações aparecidas em Riga, capital da Letónia, no ano de 1970, com colaboração também de activistas do "Movimento Judaico" de Moscovo e de Leninegrado (este "Movimento" tinha como principal objectivo a emigração e considerava impossível a sobrevivência da cultura judaica na URSS; a maior parte dos seus fundadores acabou efectivamente por emigrar e os que ocuparam os seus lugares alteraram os objectivos iniciais do movimento).

- Vestnik Ishkoda (Mensageiro do Êxodo) - que começou a ser publicado em 1971 e cuja principal informação era constituída por manifestações, greves de fome e vicissitudes por que passavam os judeus de nacionalidade soviética que pediam visto de saída da URSS.

- Bielaia Kniga Ishkoda (Livro Branco do Exodo) - que apareceu em Moscovo no ano de 1972 e que incluía conselhos destinados aos candidatos a emigrantes.

- Obozrénié (Revista) - aparecida em 1971. Como a Crónica, preocupava-se em informar acerca dos acontecimentos omitidos pela imprensa oficial; todavia, e ao contrário da Crónica, comenta e procura explicar os acontecimentos; salienta-se, no número de Outubro de 1971, um artigo dedicado ao samizdat, no qual o autor historia as publicações clandestinas surgidas na URSS desde o após-guerra (quando eram chamadas "Underwood", do nome da marca da famosa máquina de escrever), referindo designadamente os manifestos surgidos no fim do conflito por iniciativa de grupos anti-estalinistas, como a "Oposição Leninista", o "Grupo Leninista" e a "Oposição Operária".

- Svobodamislie (Pensamento Livre) - que apareceu em Dezembro de 1971 e que definia assim a sua posição: "A nossa revista propõe-se contribuir para uma troca de ideias sobre problemas actuais do Movimento Democrático; contribuir para a elaboração das formas e dos métodos de luta mais eficazes; contribuir para a difusão de informações relativamente aos factos que o Poder procura esconder; contribuir, por fim, para a denúncia das falsificações da história da URSS e do PCUS." 
- Seyatel (O Semeador) - aparece em Setembro de 1971 e, mais do que um simples órgão informativo, surge como porta-voz de um agrupamento político cuja ideologia afirmava ser socialista "científico-democrática"; o objectivo mais ou menos confessado era fazer convergir para o Movimento Democrático a intelligentzia liberal do país, transformando assim o movimento num verdadeiro partido político.

- Vietché (nome da Assembleia Popular da antiga Rússia) - inicia a publicação em Janeiro de 1970, sob a responsabilidade de Vladimir N. Ossipov, que já passara sete anos num campo pela sua responsabilidade na publicação da Fénix. Vietché definia-se como "jornal patriótico" cujo objectivo era "fazer renascer e conservar a cultura nacional russa, a herança moral e intelectual dos antepassados, prolongar a tradição dos eslavófilos e de Dostoiewsky. Embora escrita à máquina, com todas as características do samizdat, Vietché trazia o nome e a morada do seu redactor responsável, Ossipov. Negava ter preocupações de carácter político e dizia pretender apenas "afirmar a grandeza da Rússia", rejeitando a acusação de chauvinismo que lhe fora feita. Afirmava mesmo que, se ao abrigo do art $^{\circ} .125$ da Constituição (a de 1936) fosse autorizada a edição impressa, assim se faria. Apesar de todos estes cuidados, em 15 de Março de 1974, Ossipov informava os correspondentes de imprensa estrangeiros de que, "perante a ameaça de ser processado por actividade anti-soviética e anti-governamental", para a qual estava a ser provocado por agentes do KGB, cessava a publicação do Vietché.

Na linha desta última publicação aparecem posteriormente:

- Zemlya (Terra) - da qual se publicaram 9 números.

- Moskovsky Sbornik (Miscelânea de Moscovo) que resultou da fusão da Vietché com a Zemlya, sob a direcção de Leonid Borodine, que em 1967 fora preso por "agitação")

- Politicheski Dnérnik (Diário Político) - cuja existência foi revelada em Agosto de 1971 pelos jornais norte-americanos New York Times 
e Washington Post, mas que nunca foi referido por qualquer samizdat, designadamente pela Crónica. Segundo o Washington Post, seria o órgão de uma "oposição leal", constituído por um grupo de marxistas liberais, colocados em postos elevados ou relativamente elevados, do aparelho de Estado e do Partido, com o objectivo de procurarem exercer influência sobre a política do Kremlin. As ideias deste grupo estariam próximas das de Dubcek e dos seus companheiros promotores da "Primavera de Praga": mantinha-se, portanto, a confiança na revolução bolchevique e no papel dirigente do Partido Comunista. Aliás, a seguir à invasão da Checoslováquia, o Diário Político teria publicado informações sobre o tratamento sofrido pelos líderes de Praga, as quais só poderiam provir de fontes altamente colocadas.

- Dviadtchatii Biek (Século XX) - na linha do Diário Político e sob a direcção de Roy Medvedev - publicação que se define a si própria como marxista-leninista crítica do Kremlin. $\mathrm{Na}$ apresentação da Século XX, Medvedev afirma que a responsabilidade da direcção cabia a um grupo "guiado pela preocupação comum pelo desenvolvimento da sociedade socialista e das ideias socialistas na União Soviética", cujo fim básico "é também uma combinação do socialismo e da democracia". Todavia, duas semanas depois do aparecimento da Século XX, Medvedev foi chamado ao gabinete do Procurador de Moscovo e intimado a suspender a publicação, considerada "anti-soviética". Neste primeiro número haviam sido publicados dois artigos que, por motivos diferentes, se revestiam de particular importância: o primeiro, um longo estudo sobre $O$ Dom Tranquilo para concluir que Cholokov talvez não fosse o autor do romance que lhe valera o Prémio Nobel (esta opinião, que deu a volta ao Mundo, está hoje posta completamente de parte); o segundo, umas memórias de Dmitri Vipkovsky, investigador químico falecido no fim da década de 60 , sobre o trabalho forçado num campo de concentração nos anos 30. Estas memórias, que Vitkovsky intitulou Meia Vida, estiveram para ser publicadas ainda antes da morte do autor na Novy Mir, mas Tvardovsky não conseguiu autorização. Era a sombra de Um Dia na Vida de Ivan Denisovitch. 
- Prestuplenie i Nakazanie (Crime e Castigo ${ }^{(28)}$ ) - de que saíram pelo menos sete números e cujo objectivo declarado era registar os nomes e acções de prisioneiros e carcereiros nos campos de concentração, bem como os nomes dos colaboradores da polícia secreta na época das grandes depurações.

- Repatria - organizada por soviéticos de origem alemã candidatos a emigrar para a Alemanha Federal; refere principalmente os problemas encontrados para obter o visto de saída da URSS. É, portanto, mais um jornal de refuseniks do que de dissidentes.

- Crónica da Igreja Católica Lituana - em Fevereiro de 1968 saiu o seu trigésimo número (24 páginas dactilografadas) dando informação sobre presos políticos lituanos, designadamente chamando a atenção para o caso do dissidente Balys Gajauskas, preso em graves condições de saúde. Num dos artigos, o KGB é acusado de promover falsas publicações sob a forma de samizdat, com o objectivo de desacreditar os verdadeiros samizdat e os movimentos nacionalistas e religiosos lituanos.

- Ausra - outra publicação lituana, cujo nono número, com 27 páginas dactilografadas, traz a data de Janeiro de 1978. Refere principalmente várias actividades reveladoras de sentimentos nacionalistas e religiosos profundamente enraizados na Lituânia.

Enfim, nomes de publicações várias e de vária sorte poder-se-iam citar muitos mais. Estes parecem-me, porém, dos que conheço, suficientemente representativos de uma vasta gama de tendências.

\section{O Magnitizad como meio de comunicação política interna}

De entre as várias formas de comunicação política clandestina, salienta-se, pela penetração e pela própria importância literária, o magnitizdat (ou magizdat). Contracção das palavras magnetofon e izdatesltvo, magnitizdat, à semelhança de samizdat, refere-se à publicação de obras

(28) Título de uma obra célebre de Dostoiewsky. 
não aprovadas pela Censura e que são, fundamentalmente, canções de conteúdo social: as baladas.

O fenómeno dos baladeiros não é, como se sabe, exclusivo da União Soviética. À semelhança dos seus congéneres ocidentais, também eles pegam na guitarra e cantam o seu desgosto pela sociedade em que vivem; no caso soviético, os principais baladeiros distinguem-se pela altíssima qualidade dos seus versos, especialmente Bulat Okudjava, considerado talvez o maior de todos.

Bulat Okudjava nasceu em 1924, filho de pai georgiano e de mãe arménia, ambos membros do Partido Comunista (o pai foi fuzilado por "espionagem a favor do Japão" durante as grandes depurações e a mãe passou 19 anos na Sibéria, tendo sido reabilitada em 1956 e autorizada a residir em Moscovo outra vez). Aos 17 anos, o jovem Bulat alistou-se como voluntário e foi ferido em combate; estudou na Universidade de Tiblis e foi professor numa escola de aldeia na região de Kaluga, altura em que começou a escrever poesia. Em 1956, depois de publicar o seu primeiro livro de poemas, foi chamado à redaç̧ão da Literaturnaia Gazeta (Gazeta Literária) onde, ao que parece, teve uma certa influência na publicação do famoso poema de Ievutchenko "Babi Yar", em 1961, o que talvez tenha contribuído para os termos entusiásticos com que Ievutchenko se lhe refere na sua "Autobiografia": "O poeta Bulat Okudjava - escreve - corrigia enfadonhos manuscritos numa casa editora. À noite, porém, em frente de um cálice de vodka, cantava, acompanhando-se com a guitarra, as suas irrepetíveis canções-poema a dois ou três amigos, sem suspeitar que, passados poucos anos, elas teriam sido reproduzidas até ao infinito em fita gravada".

É a partir de 1960 que Okudjava ganha fama como baladeiro apesar de - conforme ele próprio escreveu - "os guitarristas me considerarem falto de talento, os compositores dizerem que não tenho profissionalismo, os cantores afirmarem que não tenho voz e todos me acusarem de impudência, de insolência e de vulgaridade [...] de os funcionários (do Partido) me acusarem de pessimismo, de antipatriotismo e de pacifismo, e de a imprensa os apoiar".

Todavia, Okudjava está longe de ser um perseguido. É, antes, uma dessas figuras extremamente controversas surgidas na ribalta depois de 1956. Membro do Partido Comunista desde 1955, criticado por Ilichev na reunião de Dezembro de 1962 atrás referida, autorizado a viajar no estrangeiro e a dar concertos, no final dos anos 60 (mas desde 1970 que 
"por motivos de saúde" não sai da URSS), ameaçado de expulsão do PCUS em 1967, Okudjava tem alguns discos editados oficialmente e deu vários concertos públicos em Moscovo, onde continua a viver.

Outra grande figura de baladeiro é Alexandre Gali, falecido há um ano, em circunstâncias mais ou menos estranhas, em Paris.

Ao contrário de Okudjava, cuja poesia é patética e dolente, Alexandre Galic escreve versos de acerada ironia e sem indulgências, abrindo o caminho à verdadeira canção de protesto. Os seus versos - que ele próprio confessa ter começado a escrever nos anos 60 , depois de conhecer a poesia de Okudjava - são amargos, satirizam a política e os costumes, são versos muito diferentes dos de Okudjava, que mostram ainda uma certa esperança. Galic era judeu e nasceu em Ginzburgo em 1919; autor dramático, viu dez das suas peças representadas nos palcos da URSS, enquanto três não foram autorizadas a subir à cena; foi membro da União dos Escritores, de onde o expulsaram em 1971; em 1968, no Festival da Primavera de Novosibirsk, deu o seu único concerto público, o qual, segundo uma crónica de Robert Kaiser, no Washington Post de 26 de Maio de 1974, foi acolhido "com extraordinário entusiasmo" por milhares de pessoas. Pouco depois, os seus concertos privados na Casa dos Escritores de Moscovo foram também suspensos. Após uma gorada tentativa para se deslocar ao estrangeiro sem perder a nacionalidade, em 1974, Galic resolveu nesse mesmo ano pedir visto para Israel, o qual the foi rapidamente concedido. A sua morte, em Abril de 1977, fez correr muita tinta: acidente ou assassínio? $O$ assunto aqui não importa, mas é curioso transcrever (até para ler, do ponto de vista soviético, a biografia de Galic) o comentário que a revista Ndelia (a mais popular da URSS) lhe dedicou nessa altura:

"Tudo começou no princípio dos anos 60, quando [Galic] abandonou praticamente o trabalho literário para compor e executar à guitarra canções que, na sua maior parte, continham calúnias. Porquê? Talvez uma crise profissional? Percebe-se facilmente que compor versos de qualidade medíocre é mais fácil do que ser um autor dramático e caluniar é sem dúvida mais simples do que criticar. Ora, terá sido uma crise moral? Álcool, discussões, ligações duvidosas - tudo isto não era segredo para os que o acompanhavam mais de perto, nem para os seus vizinhos que mais de uma vez tiveram de pedir à Polícia que chamasse à ordem esse vizinho demasiado barulhento. Por outro lado, o seu desejo de ganhar dinheiro era tal que podia falar-se de patologia [...] Para entrar nos concertos 'privados' que dava à porta fechada era preciso pagar cinco 
rublos (como termo de comparação, note-se que os bilhetes mais caros para um espectáculo no Teatro Bolshoi custam 3 rublos e 50 kopeques) por cada bilhete. Por outro lado, é absolutamente evidente que os seus 'amigos' estrangeiros ajudaram muito Galic a perder a razão".

Terceira figura importante no grupo de baladeiros é Vladimir Vysotsky, hoje com 44 anos e que começou a distinguir-se em meados dos anos 60. Actor conhecido do Teatro Taganka - um baluarte da dissidência mais ou menos autorizada - Vysotsky participou em vários filmes nos quais cantava composições de sua autoria; de um desses filmes, Vertical, foi extraído um disco. Todavia, as canções que interpretava "oficialmente" nada tinham a ver com as que cantava em reuniões privadas ou em clubes de estudantes, o que, evidentemente, despertou a ira das autoridades, não tardando a aparecer num jornal, o Sovietskaia Rossia (Rússia Soviética), um artigo acusando-o de, "em vez de arte", oferecer "vulgaridade e imoralidade" e de cantar para "gente depravada e inferior".

Embora seja, com certeza, em comparação com Okudjava e Galic, o menos perfeito sob o ponto de vista literário, Vysotsky parece ser por depoimento de emigrados soviéticos chegados ao Ocidente - o mais popular de todos e o que mais vezes tem sido reproduzido em magnitizdat. As suas baladas insistem, principalmente, no tema do anti-semitismo e na vida de um submundo que as autoridades soviéticas gostariam que não existisse e, mais ainda, que ninguém se lhe referisse.

Muitos outros nomes se poderiam citar, como os dos jovens Mikhail Nozkhine e Juli Kim, que cantam principalmente a existência dura e vulgar do cidadão soviético comum, ou os de Mikhail Ancharov, Iuri Vizbor e Novella Matveyeva, mas os baladeiros verdadeiramente importantes são, sem dúvida, Okudjava, Galic e Vysotsky. No entanto, para além dos nomes conhecidos e consagrados, não têm conta os milhares de cassetes em circulação gravadas por cidadãos de todo desconhecidos que recorreram àquele meio de comunicação para transmitir baladas da sua própria autoria e, com eles, uma crítica à sociedade em que vivem.

\section{Samokino e Samefir como meio de comunicação política interna}

Do samokino $($ Kino = Cinema) pouco há a dizer, pois trata-se de uma manifestação ainda incipiente; não só toda a aparelhagem é cara, como 
o problema de revelação e de distribuição tornam este meio de comunicação de pouca utilidade prática para os dissidentes. Produzir um filme, revelá-lo, fazer cópias e distribuí-lo são operações mais difíceis do que para o samizdat. O mais famoso exemplo de samokino é o que foi produzido em 1971 para mostrar oito das mais conhecidas figuras do Grupo de Acção para a Defesa dos Direitos Cívicos - entre os quais Iakir, A. Essenine-Volpione e Zinaide Grigorienko, descrevendo os problemas dos judeus soviéticos e dos tártaros da Crimeia e as condições dos intelectuais em hospitais psiquiátricos e insistindo na necessidade de autorizar a livre entrada e saída de pessoas da URSS e na liberdade de imprensa.

Por seu turno, e embora pouco lembrado - talvez porque é principalmente fonte de comunicação social - o samefir (efir significa éter) é, potencialmente, da maior importância, embora se saiba muito pouco do real valor (cá estamos: verba volant...) dos rádio-amadores no desenvolvimento da dissidência na URSS; e como operação de grande envergadura apenas se conhece a que foi montada na Ucrânia, em Agosto de 1968, para dar a conhecer às tropas soviéticas a verdadeira situação da Checoslováquia.

A actividade dos rádio-amadores é considerada paramilitar e, por isso, severamente vigiada pelas autoridades. Segundo números oficiosos (agência noticiosa TASS, em 27 de Outubro de 1978), estão registados na URSS 26.000 postos-rádio de utilização colectiva e individual. Ao lado destes, alguns milhares de postos clandestinos estão certamente disseminados através do território soviético, especialmente na parte europeia do país, onde é mais fácil obter os materiais necessários para construir um emissor-receptor. É evidente que, nos seus contactos com rádio-amadores de outros países, os rádio-amadores soviéticos obterão informações que, depois, por sua vez, transmitem internamente, não sendo raros os casos de transmissão em comprimentos de onda ilegais. Já por várias vezes, especialmente a partir de meados dos anos sessenta, os tribunais soviéticos foram chamados a julgar casos de emissões ilegais ou de rádio-amadores que não possuíam a necessária licença, com base no artigo $70^{\circ}$ do Código Penal ("agitação e propaganda anti-soviética").

\section{A comunicação boca a boca como meio de comunicação política interna}

Como já se disse, a comunicação boca-a-boca nada tem a ver com o boato, muito embora, evidentemente, possam ser, e por vezes sejam, 
transmitidos boatos de uma pessoa para outra. É, afinal, o mais antigo meio de comunicação: a transmissão oral, que ainda hoje reina nas pequenas comunidades rurais. Aliás, num país em que a mentalidade camponesa predomina, e é o caso da União Soviética, não surpreende a confiança nesta informação oral, como não surpreende encontrar depoimentos de judeus que emigraram da URSS segundo os quais são muitas vezes enviadas, das pequenas às grandes cidades, pessoas cuja missão é obter informações sobre assuntos que possam interessar directamente a uma determinada comunidade. Por outro lado, sendo o correio facilmente controlável, e com certeza muitas vezes censurado, não é possível confiar ao papel informações mais ou menos confidenciais. Merece muito maior confiança o telefone. Muita da informação publicada em samizdat é seguramente - a avaliar pelo curto espaço de tempo que medeia entre o evento e a sua revelação - transmitida pelo telefone e, a confirmá-lo, foi, indirectamente, o próprio Estado soviético que, por decreto de 31 de Agosto de 1972, aprovado em Conselho de Ministros, decidiu que "o uso das linhas telefónicas (interurbanas ou urbanas) para fins contrários aos interesses do Estado e à ordem pública, é proibido".

Fonte da comunicação boca-a-boca é muitas vezes a rádio estrangeira, especialmente a Voz da América e a BBC, cujas emissões já não sofrem interferências (ao contrário do que ainda sucede com a Rádio Europa Livre) e cada qual ouve à vontade. Segundo as estatísticas oficiais soviéticas, havia, em 1977, no território da URSS, por cada 1000 habitantes, 240 receptores de rádio, na sua maior parte capazes de captar as emissões estrangeiras. Aliás, este fenómeno das emissões de rádio estrangeiras para a URSS pode estar na origem de uma próxima futura evolução da imprensa oficial soviética.

\section{Conclusão}

Em 1970, Valentim Moroz ${ }^{(29)}$, um intelectual ucraniano, falando no tribunal em sua própria defesa afirmou:

(29) Foi preso em Agosto de 1965, numa vaga de repressão que atingiu igualmente dezenas de outros intelectuais ucranianos. Cumpriu quatro anos de trabalhos forçados, ao fim dos quais foi libertado, mas para ser preso pouco depois, para ser julgado e condenado a cinco anos de prisão, mais três de trabalhos forçados e outros cinco de exílio. 
“Desde 1965 que várias dezenas de pessoas foram presas. O que se obteve com isso?... Foi possível, por exemplo, deter a corrente de literatura não oficial que evita a censura e a que é dado o nome de samizdat? Não... O samizdat está a crescer e a tornar-se cada vez mais rico em conteúdo, em direcção, em colaboração e em leitores... Quis-se extinguir o fogo mas, pelo contrário, deitou-se petróleo nas chamas...".

É exactamente este o problema que, em definitivo, se levanta: o da circulação do samizdat - e, evidentemente, o de todos os outros meios clandestinos de comunicação social. Ampla? Ou restrita, sem significado, como afirmam os responsáveis da informação soviética? Evidentemente que é impossível conhecer o número exacto de cópias de cada publicação - ou cassete ou filme ... - pois teoricamente todos os que obtêm um exemplar podem reproduzir alguns mais e distribuí-los. Quantos o fazem e quantos fazem, eis a dúvida, mas é assim que circula o samizdat, seja publicação periódica, seja conto ou poesia, seja denúncia política.

Pessoalmente, penso que todas as publicações ilegais correm num círculo restrito dentro de um mesmo grupo social ou profissional.

- Gostava de conversar consigo sobre o "Dr. Jivago", disse-me, uma vez, uma professora de Literatura russa e soviética que trabalha para a UPDK, a organização estatal de apoio ao Corpo Diplomático acreditado na URSS, e que, portanto, se presume ser pessoa sem fama de dissidente ou de simpatizante da dissidência.

- Sobre o "Dr. Jivago? Mas como, se nunca foi publicado na União Soviética? - retorqui, bem sabendo qual seria a resposta.

- Claro! Mas toda a gente leu ...

Ora, esta mesma professora ignorava a existência da Crónica dos Assuntos Correntes e nem sequer mostrou grande curiosidade em saber do que se tratava. Para ela, seria mais um dos muitos samizdat que correm pela URSS. Esta atitude - que é vulgar - provoca uma outra reflexão: qual a penetração do samizdat político? Que camadas atinge? Em que medida? A reflexão sobre estes pontos poderia ocupar algumas centenas de páginas e excederia em muito o âmbito desta informação.

Todavia, gostaria de exprimir uma opinião meramente pessoal.

Quanto a mim, o samizdat político tem uma influência relativamente escassa na União Soviética. A grande massa do povo ignora-o e a camada dirigente "liberal" está muito longe de se entender sobre o tipo de 
evolução do regime. As autoridades sabem-no e a existência do samizdat pode até ajudar a detectar uma certa forma de estado de espírito da opinião pública e provocar contramedidas (algo de parecido com as cartas dos leitores aos directores dos jornais $\left.{ }^{(30)}\right)$. Por outro lado, a leitura dos samizdat não mostra a existência de grandes cabeças políticas entre os dissidentes ou resistentes. Mas dissidentes de quê ou resistentes a quê? É este o ponto importante, pois não é possível esquecer que o pensamento filosófico e político soviético é, naturalmente, herdeiro do russo e este foi enformado pela concepção bizantina e pela prática tártara que nada têm a ver com as concepções e práticas do mundo ocidental. Nesta parte do globo não houve Magna Carta, nem se ouviu alguma vez falar de Declaração dos Direitos do Homem (a da Revolução Francesa). Os que conheciam uma e outra - o que não quer dizer que concordassem - eram os que a Revolução de 1917 varreu, numa altura em que o desenvolvimento de um determinado tipo de economia parecia encaminhar a Rússia para um regime político semelhante aos ocidentais. Neste contexto, Lenine não teria sido mais do que o agente histórico que repôs a Rússia no seu caminho tradicional ${ }^{(31)}$.

Do que digo se infere que, afinal, o samizdat, a divulgação das suas ideias - e quase preferia dizer: das suas informações - não põe em risco os alicerces do Estado soviético. Como compreender as preocupações com os dissidentes? Parece-me que a explicação é uma só: todos os países socialistas europeus - com excepção da Bulgária - estiveram sempre envolvidos no processo europeu. $\mathrm{Na}$ Checoslováquia como na Hungria, na Polónia como na Roménia e na Alemanha (Oriental), as concepções políticas e filosóficas dominantes no mundo ocidental estão profundamente enraizadas e um regime de concepção oriental, bizantina, não cabe no esquema mental desses povos. Aí, sim, as massas populares são susceptíveis de se deixarem influenciar por dissidentes que defendem uma concepção de regime político que toda a gente entende. Ora, como reprimir os dissidentes nesses países e deixá-los actuar, e proliferar, na URSS?

(30) As cartas dos leitores, publicadas ou não, eram (se calhar, continuam a ser) todas lidas com atenção pelas autoridades, que por elas também mediam o estado da opinião pública.

(31) Cf. La Tradition Russe, de Tibor Szamuely. 
Poderá ser esta a explicação para a aparente contradição entre uma escassa penetração do samizdat político e a dureza da repressão. Dureza que se traduz também na expulsão de muitos dos mais prestigiosos dissidentes, o que é uma forma de neutralizá-los completamente sob o ponto de vista da influência interna.

Moscovo, 5 de Dezembro de 1978

\section{Bibliografia}

AAVV - The Dynamics of Soviet Politics, Londres, Harvard University Press, 1976. AAVV - Dissent in the URSS, The John Hopkins University Press, 1975.

GEDILAGHINE, Vladimir - Les Contestataires en URSS, Paris, Casterman, 1974. KOCHAN, Lionel - The Jews in soviet Russia Since 1917, Lionel Kochan, Oxford University Press.

LEKCHINE, Vladimir - Réponse à Soljenitsine, Paris, Albin Michel, 1978.

SZAMUELY, Tibor - La Tradition Russe, Paris, Stock, 1976.

REDDAWAY, Peter - Uncensored Russia, Londres, Jonatham Cape, Ltd.

SJEKLOCHA, Paul e MEAD, Igor - Unofficial Art in the Soviet Union, Berkeley,

Los Angeles, University of California Press, 1967.

SMITH, Hedrick - Les Russes, Paris, Éditions Pierre Belfond, 1976.

TATU, Michel - Le Pouvoir en URSS, Paris, Grasset.

ZVETEREMICH, Pietro, (org,) - Canzoni Russe di Protesta, Milão, Garzanti.

* - Já não tenho à mão todos os livros que utilizei para a elaboração do texto acima. Daí, algumas lacunas, mas pareceu-me preferível indicar, mesmo com deficiências, estas obras, a não inserir qualquer bibliografia. 